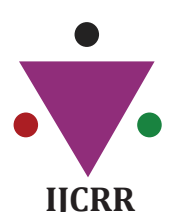

Section: Healthcare

Sci. Journal Impact

Factor: 6.1 (2018)

ICV: 90.90 (2018)

Scopus'

\title{
Corelation Between Cytological and Histological Grading of Breast Cancer and its Utility in Patient's Management
}

\author{
Pratibha Dawande ${ }^{1}$, Neha Bhatt ${ }^{2}$, Obaid Noman ${ }^{2}$, Sweta Bahadure ${ }^{3}$, \\ Arvind Bhake ${ }^{4}$, Neha Bhatt ${ }^{2}$
}

\begin{abstract}
'Associate Professor, Department of Pathology, Datta Meghe Medical College, Shalinitai Meghe Hospital and Research Centre, Nagpur-441110; ${ }^{2}$ Assistant Professor, Department of Pathology, Datta Meghe Medical College, Shalinitai Meghe Hospital and Research Centre, Nagpur-441110; ${ }^{3}$ Assistant Professor, Department of Pathology, Jawaharlal Nehru Medical College, Datta Meghe Institute of Medical Sciences, Sawangi Wardha; ${ }^{4}$ Professor Department of Pathology, Jawaharlal Nehru Medical College, Datta Meghe Institute of Medical Sciences, Sawangi Wardha.
\end{abstract}

\section{ABSTRACT}

Background: The decision on neoadjuvant therapy is often supported by tissue examination for morphology and receptor status. However, core biopsy requiring more expertise, cost and time may not be a prefered choice by many. FNAC being a simple and easily available alternative needs to be explored for this purpose.

Introduction: Breast cancer is the most common malignant tumor affecting females worldwide. With availability of better treatment options for managing these patients, the mortality assosiated with it has reduced considerably. In a country of limited resources like ours FNAC remains an easily available, cheap and less invasive modality that can be utilized not only in diagnosing malignancy but also in grading the tumors, which in turn will be useful in deciding neo adjuvanct therapy. Out of the various grading systems, Robinson's grading system is simple and time saving and hence we have selected it to be corelated with Modified Bloom Richardson's grading system.

Material and Methods: A prospective study was carried out, wherein two independant observers subjected all breast cancer patients grading by cytological and histological examination of tissue and cyto histo correlation.

Results: This study achieved good individual correlation and interobserver agreement on grading of cytopathological aspirates of breast cancers.

Conclusion: Cytopathological grading would be beneficial to these patients and hence should be routinely incorporated in reporting.

Key Words: Breast cancer, Cytopathology, Robinson's grading system, FNAC

\section{INTRODUCTION}

Carcinoma breast being the leading cancer in women worldwide has been widely researched, with resultant advanced treatment options available for it today. In Indian women also, it surpassed cervical cancer a couple of years back to become the topmost cause of cancer associated agony ${ }^{1}$. Triple assessment in breast lump cases has been accepted uniformly as best guide in managing these patients, with FNAC being one of the mainstay ${ }^{2}$. Moreover for a developing country like India with restricted resources, a simple, economic and less invasive procedure like FNAC can provide valuable information. However, the general practice is to use it only for categorizing tumours as benign and malignant, limiting the usefulness of this procedure. Core biopsy, being a costly alternative have not gained popularity here ${ }^{3,4}$. Hence, FNAC should be employed to extract maximum information about the tumour before any radical procedure, as this may help avoid or minimise surgical difficulties and associated morbidity ${ }^{5,6}$. Grading of tumor on FNAC has been a contentious issue for sometime now, but sadly no unanimous agreement has been made ${ }^{7}$. Routine incorporation of immunocytochemistry for ER, PR and Her 2 on aspirate smears may act like 'icing on the cake' in these cases 8 .

Various authors have reported Robinson's cytological grading system to be uncomplicated, objective, time saving,practical and reproducible, hence we have selected it to be correlated

\section{Corresponding Author:}

Dr. Pratibha Dawande, Associate Professor, Department of Pathology, Datta Meghe Medical College, Shalinitai Meghe Hospital and Research Centre, Nagpur-441110.

ISSN: 2231-2196 (Print)

Received: 25.05 .2020
ISSN: 0975-5241 (Online)

Revised: 18.06 .2020
Accepted: 30.06 .2020
Published: 21.07 .2020 
with Modified Bloom Richardson's histological grading system $^{9,10,11,12}$.

\section{AIM AND OBJECTIVES}

Aim: To determine utility of cytological grading in selecting neoadjuvant therapy for management of breast carcinoma.

\section{Objectives of study}

To conduct a prospective study on atleast 30 cases of breast carcinomas reported on cytology over a period of one year and evaluate its usefulness in deciding preoperative neoadjuvant therapy.

1) To evaluate and do cytomorphological grading utilizing Robinson's three tier grading system of all patients of breast carcinoma.

2) To evaluate and histopathologically grade all MRM specimens using Modified BR grading system.

3) To corelate the cytomorphological and histomorphological grading systems.

\section{MATERIAL AND METHODS}

\section{Research design and methodology}

A prospective study was carried out at DattaMeghe Medical College and Shalini Tai Meghe Hospital and research centre in association with AcharyaVinobaBhave Rural Hospital and Jawaharlal Nehru Medical College for a duration of 6 months in which all patients of breast cancer were evaluated with respect to tumourcytomorphology and histomorphology by two independent observers. Correlation between cytomorphological and histomorphological grading was done.

The data was analysed using test of significance to find out relevance of cytological grading in deciding neoadjuvant therapy.

Inclusion criteria: All operable breast cancer patients.

Exclusion criteria: All patients who have recieved any modality of preoperative chemo/radio therapy were excluded from the study.

\section{Sample collection process}

FNAC was done using $5 \mathrm{ml}$ syringe under all aseptic precautions. Material thus obtained was subjected to papanicolaou, giemsa and H\&E stain. Slides were evaluated by two independent observers and grading done using Robinson's three tier grading system.

MRM specimens were grossed and sections from the tumour evaluated and graded using Modified BR system by two independent observers.
Data thus collected was analysed and correlated.

\section{RESULTS}

Thirty two patients were included in the study. All were female and aged from 35 to 60 yrs. The average duration of presence of lump was 4 months 12 days, ranging from 15 days to 1 year. Individually observer 1 obtained good cytohisto correlation for grade II and III tumours, whereas observer 2 obtained good correlation for all grades oftumour. Two case out of three reported as grade 1 on cytopathology were upgraded to grade 2 on histopathology by observer 1. For Observer 2, two out of four cases reported as grade III tumours were downgraded to grade 2 on histopathology, whereas three out of twenty six cases reported as grade 2 on cytopathology were upgraded to grade 3 on histopathology. Both the observers obtained good agreement for cytopathological and histopathological grades respectively and no significant difference was found between individual concordance for grade 2 and grade 3 tumours, however, for grade 1 tumours inter observer concordance was significant.

\begin{tabular}{|c|c|c|c|c|c|}
\hline $\begin{array}{l}\text { BR Grading } \rightarrow \\
\text { Robinson's } \\
\text { Grading } \downarrow\end{array}$ & $\begin{array}{c}\text { Grade } \\
\quad 1\end{array}$ & $\begin{array}{c}\text { Grade } \\
2\end{array}$ & $\begin{array}{c}\text { Grade } \\
3\end{array}$ & Total & Concordance \\
\hline Grade 1 & $\mathrm{O} 1$ & 02 & oo & 03 & $33.3 \%$ \\
\hline Grade 2 & oo & 22 & 01 & 23 & $95.6 \%$ \\
\hline Grade 3 & oo & 03 & 03 & 06 & $50 \%$ \\
\hline Total & $\mathrm{O} 1$ & 27 & 04 & 32 & \\
\hline
\end{tabular}

Table 2 Observer 2: Distribution of cases according to BR histopathological grading and Robinson's cytological grading

\begin{tabular}{lccccc}
$\begin{array}{l}\text { BR Grading } \rightarrow \\
\text { Robinson's } \\
\text { Grading } \downarrow\end{array}$ & 1 & 2 & 3 & & \\
Grade 1 & 02 & 00 & 00 & 02 & $100 \%$ \\
Grade 2 & 01 & 22 & 03 & 26 & $84.6 \%$ \\
Grade 3 & 00 & 02 & 02 & 04 & $50 \%$ \\
Total & 03 & 24 & 05 & 32 & \\
\hline
\end{tabular}


Table 3: Interobserver agreement for histopathological grades

\begin{tabular}{lccccl} 
& Observer 1 & Observer 2 & к- value & \% Agreement & Agreement \\
Grade 1 & o1 & 04 & 0.368 & $90.6 \%$ & Fair \\
Grade 2 & 27 & 24 & 0.714 & $90.6 \%$ & Substantial \\
Grade 3 & 04 & 05 & 0.87 & $96.8 \%$ & Almost Perfect \\
\hline
\end{tabular}

Table 4: Interobserver agreement for cytopathological grades

\begin{tabular}{lccccc} 
& Observer 1 & Observer 2 & к- value & \% Agreement & Agreement \\
Grade 1 & 03 & 02 & 0.783 & $96.8 \%$ & Substantial \\
Grade 2 & 23 & 26 & 0.741 & $90.6 \%$ & Substantial \\
Grade 3 & 06 & 04 & 0.764 & $93.7 \%$ & Substantial \\
\hline
\end{tabular}

Table 5: Comparison of concordance of histo-cyto correlation between the two observers

\begin{tabular}{lccc} 
& Observer 1 & Observer 2 & p value \\
Grade 1 & $33.3 \%$ & $100 \%$ & $<0.0001$ \\
Grade 2 & $95.6 \%$ & $84.6 \%$ & 0.143 \\
Grade 3 & $50 \%$ & $50 \%$ & 1.0 \\
\hline
\end{tabular}

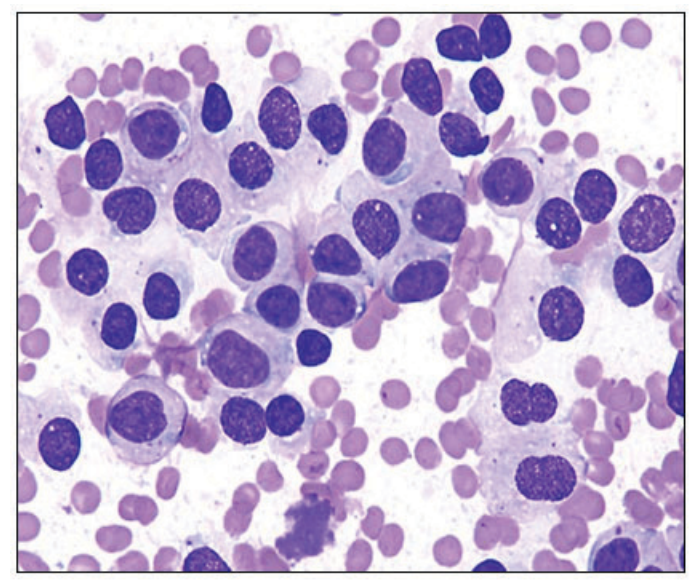

Figure 1: Photomicrograph (40X view) showing Giemsa stained breast Fine needle aspirate showing sheet of ductal cells having Irregular nuclear membrane.

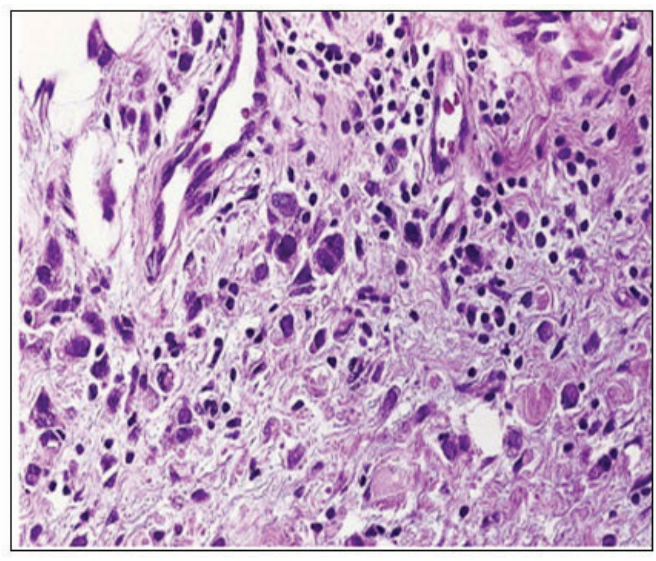

Figure 2: Photomicrograph (40X view) showing Hematoxylin and Eosin stained section of breast showing pleomorphic ductal cells.

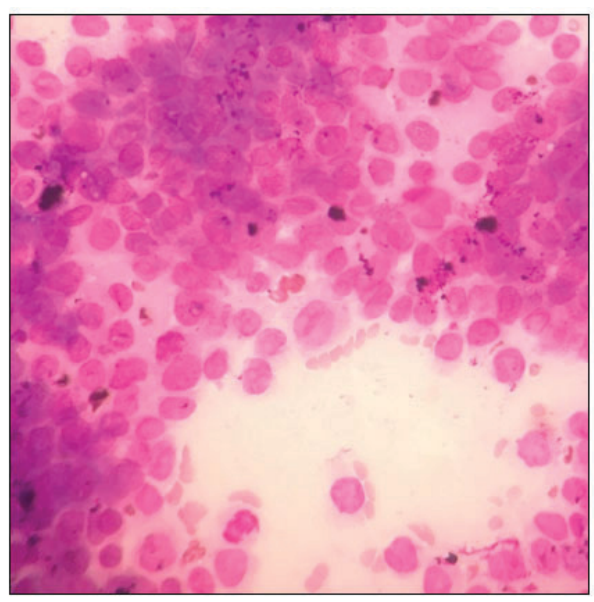

Figure 3a: H \& E stained photomicrograph (40X view) showing ductal carcinoma grade I.

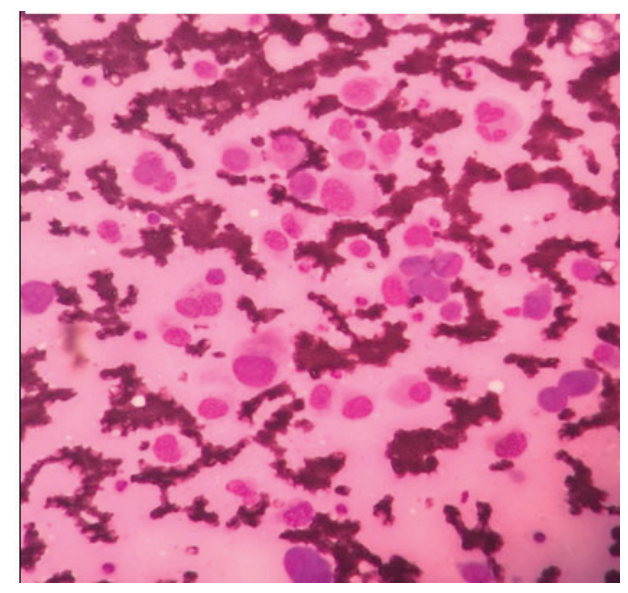

Figure 3b: H\& E stained photomicrograph (40X view) showing ductal carcinoma grade III. 


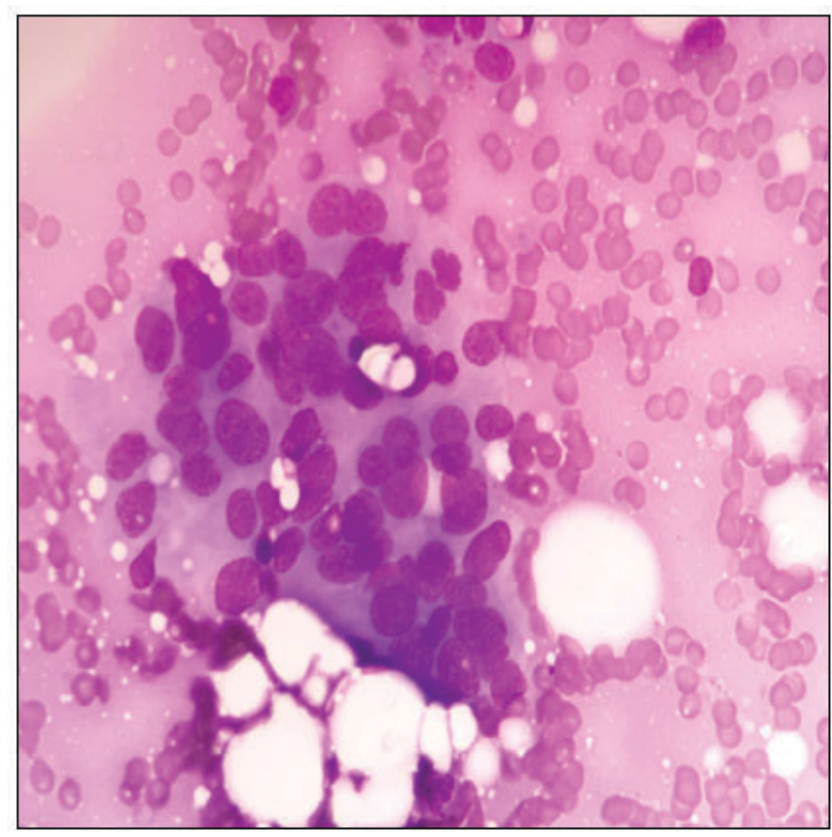

Figure 4: Giemsa stained photomicrograph (40X view) showing ductal carcinoma grade II.

\section{DISCUSSION}

Neoadjuvant therapy in the management of breast carcinoma patients was initially used to downgrade tumour, allowing breast conservation surgery in place of radical operations. With advancement, the role of neoadjuvant therapy has shifted to improving survival and prognosis in these patients. Many genetically targeted chemotherapeutic and hormonal drugs are used for this purpose ${ }^{13}$. Grade of tumour is a reflection of changes occurring at the molecular level as different grades of tumour exhibit different genetic changes ${ }^{14}$. Offering grading on cytopathological examination of FNAC aspirates can prove beneficial in selecting patients for neoadjuvant therapy and selecting neoadjuvant therapy in these patients ${ }^{15}$. Out of the various cytopathological grading systems Robinson's has been studied extensively and correlates well with histopathological grade. Many authors found good correlation of Robinson's cytopathological grading with BR Histopathological grading, being more than $80 \%$ in studies by Sultana and Rehman, Meena et al., Kalhan et al., Rekha et al., Sinha et al., Bhargava et al. and Khan et al. ${ }^{16,17,18,19,20,21,22}$. Robinson himself found 57\% correlation, whereas Lingegowda, Chabra, and Das found $64 \%, 65 \%$ and $71.2 \%$, respectively ${ }^{6,23,24,25}$.

In the present study too, both the observers got good cytohisto correlation for grade 2 and 3 tumors. However, for grade 1 tumors one of the authors got only $33.3 \%$ correlation while the other got $100 \%$. This bias could have resulted as the overall sample size was less and very few tumours fell into this category. Even with this bias, the interobserver agreement achieved was good for all grades of tumor.
Robinson's system considers cellular cohesion, size, and unifomity as well as nuclear features like characteristics of nucleoli, nuclear margin, and chromatin for assigning grades to the aspirates ${ }^{6}$. On regression analysis, all cytological features included were of equal importance, especially the inclusion of nucleolar features gave an extra benefit. However, exclusion of mitosis is drawback with this system ${ }^{26}$. Loss of cell cohesion is a well-recognised feature for diagnosing any epithelial malignancy. In breast carcinomas too, cellular discohesion carries utmost importance in grading and predicting lymph node metastasis, hence influencing staging, $6,27,28,29,30$. Cell size is influenced by the fragility of cytoplasm in malignant cells, hence replacing it with nuclear size and including nuclear-cytoplasmic ratio would enhance the outcome of reporting ${ }^{22,31,32}$. Pleomorphism encompassing variation of cell/nuclear size, shape, and staining characteristic, though subjective, has been found to be a simple and easy criteria for grading by many $y^{33,34,35}$. Nucleolar characteristics have been established as an important criterion in prognostication of breast carcinomas ${ }^{36,37}$. Although nuclear margin and chromatin pattern gets partially assessed under pleomorphism, both play significant independent roles in grading of tumors ${ }^{6,22,38,39}$. DCIS and invasive carcinomas, both can aspirate necrotic material on cytological smears, and hence using necrosis as grading criteria can become tricky ${ }^{22}$. Mitotic count depicts the aggressiveness of any malignancy and correlates significantly with tumour grade on cytopathological aspirates ${ }^{18,40,41}$. Marked lymphocyte response in invasive ductal carcinomas is associated with ER and PR negativity and hence can prove valuable in deciding neoadjuvant therapy ${ }^{42}$. However, this criteria did not gain good cyto-histo correlation in many studies ${ }^{22,39}$.

The assessment of various grading criteria on aspirate smears is influenced by sampling bias. Also all the cytopathological grading systems are based on IDC-NOS ${ }^{7}, 39$. Nevertheless, IDC-NOS comprises the most common tumour variant and hence these patients should be given the benefit of cytopathological grading ${ }^{43}$. Grading on cytolopathogical aspirates has been supported by the National Institute of Cancer, Bethesda in their workshop on a uniform approach to breast fine-needle aspiration biopsy ${ }^{44}$. As in our study, the interobserver agreeability has been good in various other studies ${ }^{9}$. 23,45 .

\section{CONCLUSION}

To conclude consensual criteria need to be laid down to increase objectivity and uniformity of reporting grade on aspirate smears. These may include the number of passes for particular tumor size, adequacy of smears, staining preferences, and cytomorphological criterias.

Acknowledgement: None 


\section{Conflict of interest: None}

Financial support: None

\section{REFERENCES}

1. Gupta S. Breast cancer: Indian experience, data, and evidence. South Asian J Cancer. 2016 Jul-Sep; 5(3):85-6.

2. Zagorianakou P, Fiaccavento S, Zagorianakou N, Makrydimas G, Stefanou D, Agnantis NJ. FNAC: Its role, limitations and perspective in the preoperative diagnosis of breast cancer. Eur J Gynaecol Oncol 2005; 26.143-9.

3. Berner A, Davidson B, Sigstad E, Risberg B. Fine-needle aspiration cytology vs. core biopsy in the diagnosis of breast lesions. DiagnCytopathol 2003;29:344-48.

4. Silverman JF, Elsheikh TM, Singh HK. The role of fine needle aspiration cytology of the breast in the core biopsy era. Pathol Case Rev 2007;12:44-48.

5. Richards MA, Smith IE, Dixon JM.ABC of breast diseases. Role of systemic treatment for primary operable breast cancer. BMJ 1994;309:1363-6.

6. Robinson IA, McKee G, Nicholson A, D’Acry J, Jackson PA, Cook MG, et al. Prognostic value of cytological grading of fineneedle aspirates from breast carcinomas. Lancet 1994;343:947-9.

7. Bansal C, Pujani M, Sharma KL, Srivastava A N, Singh U S. Grading systems in the cytological diagnosis of breast cancer: A review. J Can Res Ther 2014;10:839-45

8. Toi PC, Neelaiah S, Dharanipragada K, Surendra K. Evaluation of Estrogen and Progesterone Receptors and Her-2 Expression with Grading in the Fine-needle Aspirates of Patients with Breast Carcinoma. J Cytol. 2018;35(4):223-228.

9. KaushikSaha, Gargi Raychaudhuri. Comparative evaluation of six cytological grading systems in breast carcinoma. Journal of Cytology 2013;30(2): 87-93.

10. Odujoko O., Omoniyi-Esan G., Komolafe A., Sabageh D. The Comparison between Cytological and Histological grading of Breast Cancers in a Nigerian tertiary hospital Res. J. of Health Sci. Vol 7(1), Jan./Mar., 2019, p10-18

11. Wani FA, Bhardwaj S, Kumar D, Katoch P. Cytological grading of breast cancers and comparative evaluation of two grading systems. J Cytol. 2010;27(2):55-58.

12. Pal S, Gupta ML. Correlation between cytological and histological grading of breast cancer and its role in prognosis. J Cytol. 2016;33(4):182-186.

13. Cigdem Selli, Andrew H Sims. Neoadjuvant therapy for breast cancer as a model for translational research. Breast cancer: Basic and clinical research. 2019; 13: 1-7

14. Li Y, Wang X, Vural S, Mishra NK, Cowan KH, Guda C. Exome analysis reveals differentially mutated gene signatures of stage, grade and subtype in breast cancers. PLoS ONE. 2015; 10(3): $\mathrm{e} 0119383$

15. Katz RL. A turning point in breast cancer cytology reporting: Moving from callowness to maturity. ActaCytol. 1994;38:881-3

16. Sultana T, Rahman AJ. Cytological grading of duct cell carcinoma NOS of breast and its correlation with histological grading. Bangladesh Med Res Counc Bull.2006; 32:49-54.

17. Meena SP, Hemrajani DK, Joshi N. A comparative and evaluative study of cytological and histological grading system profile in malignant neoplasm of breast - An important prognostic factor. Indian J Pathol Microbiol 2006;49:199-202.

18. Kalhan S, Dubey S, Sharma S, Dudani S, Preeti, Dixit M. Significance of nuclear morphometry in cytological aspirates of breast masses. J Cytol. 2010;27:16-21.
19. Rekha TS, Nandini NM, Dhar M. Validity of different cytological grading systems of breast carcinoma- a hospital based study in south India. Asian Pac J Cancer Prev. 2011;12:3013-6.

20. Sinha S, Sinha N, Bandyopadhyay R, Mondal SK. Robinson's cytological grading on aspirates of breast carcinoma:Correlation with Bloom Richardson's histological grading. J Cytol 2009;26:140-3.

21. Bhargava V, Jain M, Agarwal K, Thomas S, Singh S. Critical appraisal of cytological nuclear grading in carcinoma of the breast and its correlation with ER/PR expression. J Cytol 2008;25:5861.

22. Khan MZ, Haleem A, Al Hassani H, Kfoury H. Cytopathological grading, as a predictor of histopathological grade, in ductal carcinoma (NOS) of breast, on air-dried Diff-Quik smears. Diagn Cytopathol 2003;29:185-93.

23. Lingegowda JB, MuddeGowda PH, Ramakantha CK, Chandasekar HR. Cytohistological correlation of grading in breast carcinoma. DiagnCytopathol. 2011; 39:251-7.

24. Chhabra S, Singh PK, Agarwal A, Singh SN, Bhagoliwal A. Cytological grading of breast carcinoma-a multivariate regression analysis. J Cytol 2005;22:62-5.

25. Das AK, Kapila K, Dinda AK, Verma K. Comparative evaluation of grading of breast carcinomas in fine needle aspirates by two methods. Indian J Med Res 2003;118:247-50.

26. Robles Frías A, González Cámpora R, Martínez Parra D, Robles FríasMJ, Vázquez Cerezuela T, Otal Salaverri C, et al. Robinson cytologic grading of invasive ductal breast carcinoma: Correlation with histologic grading and regional lymph node metastasis. Acta Cytol 2005;49:149-53.

27. Wallgren A, Silfversward C, Zajicek J. Evaluation of needle aspirates and tissue sections as prognostic factors in mammary carcinoma. ActaCytol 1976;20:313-8.

28. Abati A, Abele J, Bacus SS, Bedrossian C, Beerline D, Bibbo $\mathrm{M}$ et al. The uniform approach to breast fine needle aspiration biopsy. Diagn Cytopathol 1997;81:16-21.

29. Zoppi JA, Pellicer EM, Sundblad AS. Cytohistologic correlation of nuclear grade in breast carcinoma.ActaCytol. 1997;41:701-4.

30. Gordon H. Yu, Ricardo S. Cajulisand Denise V. S. De frias. Tumor Cell (Dys)cohesion as a Prognostic Factor in Aspirate Smears of Breast Carcinoma. Ajcpath 1998; 109(3):315-19.

31. Zajdela A, De LaRiva LS, Ghossein NA.The relation of prognosis to the nuclear diameter of breast cancer cells obtained by cytological aspiration.ActaCytol 1979;23:75-80.

32. Mossler JA, McCarty KS Jr., Woodard BH, Mitchener LM, Johnston WW.Correlation of mean nuclear area with estrogen receptor content in aspiration cytology of breast carcinoma.ActaCytol 1982:26:417-21.

33. Pienta KJ, Coffey DS. Correlation of nuclear morphometryand progression of breast cancer. Cancer 1991;68:2012-6.

34. Schmoller, Kurt M.; Skotheim, Jan M. (December 2015). "The Biosynthetic Basis of Cell Size Control”. Trends Cell Biol. 25 (12): 793-802.

35. KuenenBoumeester V, Hop WC, Blonk DI, Boon ME. Prognostic scoring using cytomorphometry and lymph node status of patients with breast carcinoma.Eur $\mathrm{J}$ of Cancer ClinOncol 1984:20:337-45.

36. Black MM, Speer FD. Nuclear structure in cancer tissues.SurgGynecolObstet 1957; 105: 97-102.

37. Van Diesta PJ, Mouriquand J, Schipper NW, Baak JP. Prognostic value of nucleolar morphometric variables in cytological breast cancer specimens. J Clin Pathol 1990;43:157-9.

38. Taniguchi E, Yang Q, Tang W, Nakamura Y, Shan L, Nakamura $\mathrm{M}$ et al. Cytological grading of invasive breast carcinoma- correlation with clinicopathologic variables and predictive value of nodal metastasis. ActaCytol 2000:44:587-91. 
39. Chandanwale SS, Mishra N, Kaur S, Paranjape S, Pandey A, Jha M. Comparative analysis of six cytological grading systems in breast carcinoma. Clin Cancer Investig J 2016;5:409-15.

40. Patel C, Sidhu KP, Shah MJ, Patel SM.Role of mitotic counts in the grading and prognosis of the breast cancer.Indian $\mathrm{J}$ PatholMicrobiol. 2002 Jul;45(3):247-54.

41. Sculte E, Wittekind C. The influence of the wet fixed papnicolaou and air dried Giemsa techniques on nuclear parameters in breast cancer cytology: A cytomorphometric study. DiagnCytopathol 1987;3:256-61.
42. Rosen's breast pathology. Chapter 14: p341

43. Makki J. Diversity of Breast Carcinoma: Histological Subtypes and Clinical Relevance. Clin Med Insights Pathol. 2015;8:2331.

44. The uniform approach to breast fine-needle aspiration biopsy. National Cancer Institute Fine Needle Aspiration of Breast Workshop Subcommittees. Diagn Cytopathol 1997;16:295-311.

45. Howell LP, Gandour-Edwards R, O'Sullivan D. Application of the Scarff-Bloom-Richardson tumor grading system to fine-needle aspirates of the breast. Am J Clin Pathol. 1994;101:262-5. 